\title{
Study of heterosis analysis in $\mathbf{F}_{1}$ population of bread wheat
}

\author{
Aamir Ali Khokhar ${ }^{1}$, Wajid Ali Jatoi ${ }^{2}$, Feroz Gul Nizamani², Raza Ali \\ Rind $^{2}$, Mir Muhammad Nizamani ${ }^{*}$, Hua-Feng Wang ${ }^{1}$, Anum \\ Mehmood $^{3}$ and Muhammad Uzair Khokhar ${ }^{4}$
}

1. Hainan Key Laboratory for Sustainable Utilization of Tropical Bioresources, Institute of Tropical Agriculture and Forestry, Hainan University, Haikou-China

2.Department of Plant Breeding and Genetics, Sindh Agriculture University Tandojam-Pakistan

3. College of Molecular Biology and Biochemistry, College of Tropical Agriculture and Forestry, Hainan

University-China

4. Department of Entomology, Sindh Agriculture University Tandojam-Pakistan

*Corresponding author's email: mirmohammadnizamani@outlook.com

Citation

Aamir Ali Khokhar, Wajid Ali Jatoi, Feroz Gul Nizamani, Raza Ali Rind, Mir Muhammad Nizamani, Hua-Feng

Wang, Anum Mehmood and Muhammad Uzair Khokhar. Study of heterosis analysis in $\mathrm{F}_{1}$ population of bread wheat. Pure and Applied Biology. Vol. 8, Issue 2, pp1757-1770. http://dx.doi.org/10.19045/bspab.2019.80119

\begin{tabular}{llll}
\hline \hline Received: 06/03/2019 & Revised: 12/06/2019 & Accepted: 20/06/2019 & Online First: 24/06/2019 \\
\hline \hline
\end{tabular}

\section{Abstract}

The study was conducted to evaluate heterotic in bread wheat during crop season 2016-2017. Six parents of bread wheat (Triticum aestivum L.) were crossed in a half diallel design and their fifteen the first filial genration $\left(\mathrm{F}_{1} \mathrm{~s}\right)$ were evaluated for heterosis for yield traits. The traits included: Days to $50 \%$ heading, Days to $75 \%$ maturity, Plant height $(\mathrm{cm})$, Tillers plant ${ }^{-1}$, Peduncle length $(\mathrm{cm})$, Spike length (cm), Spikelets spike ${ }^{-1}$, Grains spike ${ }^{-1}$, Grain weight spike ${ }^{-1}(\mathrm{~g})$, Seed index (1000grain weight, g) and Grain yield plant ${ }^{-1}(\mathrm{~g})$. The analysis of variance due to genotypes, parents, hybrids and parents vs. hybrids were significant for all the characters which showed the presence of the significant amount of variability among parents, their hybrids and among parents vs. hybrids for all characters studied. Heterotic effects, the cross combinations such as WL-711 x Aas-2011 followed by Janbaz x Aas-2011 by expressing maximum desirable negative relative heterosis and heterobeltiosis were found advantageous for days to 50\% heading and days to $75 \%$ maturity; Janbaz x Aas-2011 exhibited desirable negative heterosis for plant height; Sunco x Marvi-2000 followed by Sunco x Janbaz manifested desirable positive heterosis for tillers plant ${ }^{-1}$; Sunco $\mathrm{x}$ Janbaz for peduncle length, spike length and grain yield plant ${ }^{-1}$; Janbaz x Marvi-2000 for spikelets spike $^{-1}$ and grains spike ${ }^{-1}$; Sunco x Pak-81 for grain weight spike ${ }^{-1}$ and seed index. The superiority of the above crosses over their better parents indicated their worth for hybrid crop development.

Keywords: Bread wheat; Diallel; $\mathrm{F}_{1}$ hybrids; Heterobeltiosis; Relative heterosis

\section{Introduction}

Wheat is the most widely grown crop in the world. Wheat (Triticum aestivum L.) It is one of the first domesticated food crops and has been the staple food of the main civilizations of Europe, West Asia, and North Africa for the last 8000 years. Approximately one-sixth of all arable land in the world is under wheat. This is the most demanded food grain and its production is ahead of all crops, including rice, corn, and potatoes. Wheat, as food for humans, is valued for its taste and as a source 
of calories, protein, and certain vitamins and minerals, is the most important crop in the world. Important to add to its use for bread large quantities of wheat are used for unleavened bread, such as Chapati in Pakistan and India, for confectionery and for products from semolina. These uses, combined with its nutritional value and storage quality, have made wheat the staple food for more than one-third of the world's population. As a rule, varieties of durum wheat are used for bread flour and pasta, and soft varieties are used for flour. The optimum growing temperature is about $25^{\circ} \mathrm{C}$, with minimum and maximum growth temperatures from $3{ }^{\circ}$ to $4^{\circ} \mathrm{C}$ and from $30^{\circ}$ to $32{ }^{\circ} \mathrm{C}$, respectively [1].

Pakistan's 2018/2019 wheat production is estimated at 26.3 million metric tons (MMT), 800,000 tons higher than current the United States Department of Agriculture (USDA) estimate. Growing conditions were generally good and farmers appear to have countered the potential ill effects of unseasonal rains during harvest in some areas. The Government of Pakistan procured 5.9 million metric tons (MMT) of wheat from the recently concluded wheat harvest three percent lower than the 6.1 MMT target that was announced prior to the onset of harvest and six percent less than the last year's procurement of 6.28 million metric tons (MMT). Procurement seems to have been influenced by a new mechanism for handing out bags of horns to farmers in Punjab. Many farmers were unaware of the change in policy and missed the deadline for applying for the gunny bags [2].

Wheat is nutritionally rich cereal having a significant role in food security, reducing poverty and enhancing revenue sources. For providing food to rising human population, it is predicted that in 2030, the world wheat production will reach 100 million metric tons to accomplish this target and production of wheat should be raised at the pace of 1 million metric tons per annum [3]. Plant breeders throughout the world are using genetic resources to meet the targets of the growing human population. The basic purpose of a wheat breeding program is to evolve new high yielding varieties with improved desirable characters. New varieties could be produced by applying techniques like introduction, selection, hybridization, mutation, and genetic engineering. There are two major studies in any hybrid crops i.e. heterosis and combining ability [4]. Analysis of the diallele is useful for breeders when making decisions regarding the type of breeding method used and the selection of the most promising breeding materials. Diallel is a mating system that includes all possible crosses in a group of parents. This genetic design is used to study the polygenic systems that define quantitative traits. Diallel mating models were used mainly to estimate genetic abnormalities when parents are either random individuals or inbred lines from a random mating population in linkage equilibrium. Among the various forms of the diallele, halfdiallel techniques have certain advantages over others, providing maximum information about the genetic architecture of the trait, parents and allele frequency [5]. Various workers have proposed various forms of semi-diallet analysis. [6] used semi-diallel analysis to combine abilities, while [7] using the method of multiple regression with increasing steps, heterotic effects were further separated, and both general and specific effects of the unifying ability and components of the action of genes were obtained.

Heterosis is considered a major revolution in classical plant breeding era [8]. Utilization of heterosis in a plant breeding program is one of the great achievements and exploitation of heterosis approach done within crossing wheat is much efficient than conventional breeding methods [9]. The concept of hybrid vigor or heterosis was described by [10]. 
Heterosis term describes the improved ability as compared to their parents, increase in growth, yield and other plant traits are known as hybrid vigor or heterosis. Utilization of heterosis has substantial influence in genetics to provide hybrid vigor, consequently high yielding hybrids in different crops and plants. Yield increase from heterotic hybrids due to the expression of heterosis is up to $30 \%$ superior to conventional varieties. Heterosis was first observed in wheat by [11] when studied heading time, plant height and leaf width. Heterotic effects can be seen in the form of higher plant height, more ears per plant, higher grains per ear, kernel weight, grain yield per plant, maturity, and some other characters [12]. Generally, heterosis is more used in cross-pollinated crops against self-pollinated [4]. Production of wheat probably is increased by developing new cultivars having a broader genetic base with improved performance under different environmental conditions [13]. Various techniques to analyze all possible crosses and genotypes are developed by earlier researchers. Applying heterotic effects is a significant strategy to improve yield in wheat [14]. Heterosis for grain yield will be advantageous if there is a more genetic difference between parents [15]. Selection of superior genotypes is the key step to develop higher yielding offspring and identification of superior hybrid combinations is a major subject in the wheat breeding program [16]. Heterosis has been observed in many types of crops and has been the subject of considerable importance for study as a means of increasing the productivity of crops. It is now well known that heterosis occurs with the right combination of parents [17].

Objectives

1. To workout mid and better parent heterosis in $F_{1}$ generation of bread wheat

2. To estimate heterosis in the experimental hybrids for grain yield and contributing traits.

\section{Materials and methods}

The studies were conducted during rabi season 2016-17 at Botanical Garden, Department of Plant Breeding and Genetics, Faculty of Crop Production Sindh Agriculture University, Tando Jam. Six bread wheat cultivars were crossed in Half-diallel fashion. The experiment was laid out in Randomized Complete Block Design (RCBD) with three replications. The distances between plant to plant and row to row were kept at 1.5-row length and row to row distance of $30 \mathrm{~cm}$ was kept respectively. Ten plants per genotype per replication were randomly selected and phenotypic assessment was done.

\section{Statistical Analysis}

The analysis of variance was carried out according to statistical methods developed by [18], so as to determine differences among the parents and the $F_{1} s$.

\section{Diallel analysis and gene action}

Griffing's Method-2 Model-1 = n (n-1)/2 = parents $+F_{1}$ hybrid were used.The diallel analysis was carried out according to [6] numerical approach as adopted by [19]. The analysis determined additive and nonadditive variances and effects for various traits.

\section{Heterotic effects in $\mathrm{F}_{\mathbf{1}}$ hybrids}

The percent increase (+) or decrease (-) of $\mathrm{F}_{1} \mathrm{~S}$ over mid or better parents were obtained to estimate heterotic effects according to [20] as under:

Mid-parent heterosis $\%=\frac{F_{1}-M P}{M P} \times 100$

Better parent heterosis $\%=\frac{F_{1}-B P}{B P} \times 100$

Where $F_{1}=$ Hybrid performance

M.P. = Mid-parent value (The mean of both parents)

B.P. = Better parent value (The mean of a better parent)

Ten plants per replication from each $F_{1}$ hybrid or parents were randomly selected and 
indexed to record the data for the following traits. The data were recorded in the following manner.

\section{Days to $50 \%$ heading}

It was counted in days from sowing to the emergence of $50 \%$ spikes from flag leaf.

\section{Days to $75 \%$ maturity}

Days to $75 \%$ maturity was taken when $75 \%$

of plants showed yellow peduncle, thus reached to $75 \%$ physiological maturity.

\section{Plant height (cm)}

Plant height (excluding awns) was measured from soil surface to the tip of the spike at about half grain filling stage.

Number of tillers plant ${ }^{-1}$

The number of tillers in each selected plant per replication per genotype were counted at the time of crop harvest and was recorded as the number of tillers per plant.

\section{Peduncle length}

Peduncle length was measured in centimeters from the base of the spike to the first node of the stem.

\section{Spike length (cm)}

Length of the spike of the main tiller was measured in centimeters from the base of the spike to the uppermost spikelets, excluding awns.

\section{Number of spikelets spike ${ }^{-1}$}

The numbers of spikelets per spike of each tagged plant were counted and the information was recorded as no. of spikelets spike $^{-1}$.

Number of grains spike $e^{-1}$

The total number of seeds of randomly selected spikes were counted and the average number of seeds per spike was recorded.

\section{Grain weight spike ${ }^{-1}$}

Grain weight spike $^{-1}$ was taken by threshing each spike separately and weighed in grams with electric balance.

\section{Seed index (weight of $\mathbf{1 0 0 0}$ grains in g)}

One thousand grains were randomly taken from each selected sample and weighed in grams on electric balance.

Grain yield plant ${ }^{-1}(\mathrm{~g})$

After harvesting, each plant was threshed separately with single plant wheat thresher and clean seeds were obtained for laboratory studies. The grains were weighed on an electric balance and yield per plant in gm was recorded.

\section{Results}

The present research was carried out to evaluate heterosis and heterobeltiosis in different varieties of bread wheat for various traits such as days to $50 \%$ heading, days to $75 \%$ maturity, plant height, tillers plant $^{-1}$, peduncle length, spike length, spikelets spike ${ }^{1}$, grains spike ${ }^{-1}$, grain weight spike $^{-1}$, seed index (1000 grain weight in g) and grain yield plant $^{-1}(\mathrm{~g})$. Six parents were crossed in halfdiallel mating fashion; therefore, fifteen possible cross combinations $\left(\mathrm{F}_{1 \mathrm{~s}}\right)$ were obtained.

The $F_{1}$ hybrids were tested by analysis of variance, heterosis, and heterobeltiosis. Results regarding mean squares are indicated in (Table 1). While results regarding with heterosis and heterobeltiosis for different characters are shown in (Tables $2 \& 4$ ). 
Table 1. Analysis of variance for different characters

\begin{tabular}{|c|c|c|c|c|c|c|c|c|c|c|c|c|}
\hline $\begin{array}{l}\text { Source of } \\
\text { variation }\end{array}$ & D.F & $\begin{array}{c}\text { Days to } \\
50 \% \\
\text { heading }\end{array}$ & $\begin{array}{c}\text { Days to } \\
75 \% \\
\text { maturity }\end{array}$ & $\begin{array}{c}\text { Plant } \\
\text { height }\end{array}$ & $\begin{array}{l}\text { Tillers } \\
\text { plant }^{-1}\end{array}$ & $\begin{array}{l}\text { Peduncl } \\
\text { e length }\end{array}$ & $\begin{array}{l}\text { Spike } \\
\text { length }\end{array}$ & $\begin{array}{c}\text { Spikel } \\
\text { etsspi } \\
\mathbf{k e}^{-1} \\
\end{array}$ & $\begin{array}{l}\text { Grain } \\
\text { s } \\
\text { spike }^{-1} \\
\end{array}$ & $\begin{array}{c}\text { Grain } \\
\text { weight } \\
\text { spike }^{-1} \\
\end{array}$ & $\begin{array}{l}\text { Seed } \\
\text { index }\end{array}$ & $\begin{array}{c}\text { Grain yield } \\
\text { plant }^{-1}\end{array}$ \\
\hline Replication & 2 & 0.68 & 0.68 & 5.05 & 0.33 & 86.53 & 0.23 & 4.00 & 40.33 & 0.12 & 58.92 & 4.76 \\
\hline Genotypes & 20 & $29.94 * *$ & $58.79 * *$ & $\begin{array}{c}234.15 \\
* *\end{array}$ & $11.69 * *$ & $68.29 * *$ & $6.66 * *$ & $9.10 * *$ & $\begin{array}{c}105.97 \\
* *\end{array}$ & $1.47 * *$ & $\begin{array}{c}55.04 * \\
*\end{array}$ & $96.87 * *$ \\
\hline Parent & 5 & $9.25 * *$ & $3.92 * *$ & $\begin{array}{c}226.18 \\
* *\end{array}$ & $3.55 * *$ & $73.83 * *$ & $5.31 * *$ & $\begin{array}{c}27.73^{*} \\
*\end{array}$ & $\begin{array}{c}49.12 * \\
*\end{array}$ & $2.47 * *$ & $61.58 *$ & $27.20 * *$ \\
\hline Hybrids & 14 & $28.22 * *$ & $72.04 * *$ & $\begin{array}{c}252.86 \\
* *\end{array}$ & $5.06 * *$ & $50.17 * *$ & $3.85 * *$ & $21.31 *$ & $\begin{array}{c}71.99 * \\
*\end{array}$ & $0.91 * *$ & $41.75^{*}$ & $20.22 * *$ \\
\hline Parent Vs. Hybrids & 1 & $157.5^{* *}$ & $147.66^{* *}$ & $12.02 *$ & $\begin{array}{c}150.59 * \\
*\end{array}$ & $\begin{array}{c}294.18 * \\
*\end{array}$ & $52.7 * *$ & $\begin{array}{c}293.50 \\
* *\end{array}$ & $\begin{array}{c}865.91 \\
* *\end{array}$ & $4.37 * *$ & $\begin{array}{c}208.42 \\
* *\end{array}$ & $1518.23 * *$ \\
\hline Error & 40 & 0.63 & 0.91 & 5.85 & 0.80 & 20.31 & 0.33 & 2.53 & 17.08 & 0.35 & 30.75 & 1.26 \\
\hline
\end{tabular}

$* *, *=$ Significant at 1 and 5\% probability levels respectively 
Table 2. Heterotic effects of $\mathrm{F}_{1}$ hybrids over their mid and better parents for days to $50 \%$ heading, days to $75 \%$ maturity, plant height, number of tillers plant ${ }^{-1}$ in bread wheat (Triticum aestivum $\mathbf{L}$.)

\begin{tabular}{|c|c|c|c|c|c|c|c|c|}
\hline \multirow{2}{*}{ F $_{1}$ Crosses } & \multicolumn{2}{|c|}{$\begin{array}{c}\text { days to } \\
\mathbf{5 0 \%}\end{array}$} & \multicolumn{2}{c|}{$\begin{array}{c}\text { days to 75\% } \\
\text { maturity }\end{array}$} & \multicolumn{2}{c|}{ plant height } & \multicolumn{2}{c|}{$\begin{array}{c}\text { Number of tillers } \\
\text { plant }\end{array}$} \\
\cline { 2 - 9 } & $\begin{array}{c}\text { Mid } \\
\text { parent }\end{array}$ & $\begin{array}{c}\text { Better } \\
\text { parent }\end{array}$ & $\begin{array}{c}\text { Mid } \\
\text { parent }\end{array}$ & $\begin{array}{c}\text { Better } \\
\text { parent }\end{array}$ & $\begin{array}{c}\text { Mid } \\
\text { parent }\end{array}$ & $\begin{array}{c}\text { Better } \\
\text { parent }\end{array}$ & $\begin{array}{c}\text { Mid } \\
\text { parent }\end{array}$ & $\begin{array}{c}\text { Better } \\
\text { parent }\end{array}$ \\
\hline Sunco x Janbaz & -8.89 & -10.09 & -6.48 & -6.92 & 8.71 & 4.57 & 86.67 & 82.53 \\
\hline Sunco x WL-711 & -5.62 & -7.89 & -4.76 & -5.66 & 0.66 & -7.15 & 27.66 & 20.05 \\
\hline Sunco x Aas-2011 & -3.40 & -6.58 & -3.50 & -4.72 & -5.63 & -15.72 & 61.90 & 54.62 \\
\hline Sunco x Pak-81 & -7.38 & -9.21 & -6.16 & -6.60 & -4.85 & -13.11 & 30.43 & 25.00 \\
\hline Sunco x Marvi-2000 & 0.00 & -2.63 & 4.31 & 2.83 & 3.14 & 1.39 & 89.47 & 63.71 \\
\hline Janbaz x WL-711 & -7.52 & -8.56 & -4.31 & -4.76 & -7.19 & -11.15 & 25.00 & 20.05 \\
\hline Janbaz x Aas-2011 & -8.97 & -10.81 & -7.84 & -8.57 & -15.59 & -21.88 & 53.49 & 43.42 \\
\hline Janbaz x PAK-81 & -6.12 & -6.76 & -5.71 & -5.71 & -3.78 & -8.86 & 34.04 & 31.25 \\
\hline Janbaz x Marvi-2000 & -2.74 & -4.05 & 1.92 & 0.95 & -5.36 & -7.43 & 38.46 & 17.34 \\
\hline WL-711 x Aas-2011 & -10.70 & -11.52 & -9.32 & -9.62 & 9.15 & 5.35 & 42.22 & 28.05 \\
\hline WL-711 x Pak-81 & -6.42 & -5.99 & -6.22 & -5.77 & 7.84 & 6.65 & 26.53 & 24.05 \\
\hline WL-711 x Marvi- & 2.54 & 2.31 & 4.35 & 3.85 & -8.92 & -14.64 & 31.71 & 8.04 \\
\hline 2000 & -6.94 & -8.22 & -6.88 & -7.62 & 6.98 & 4.38 & 63.64 & 50.00 \\
\hline Aas-2011 x Pak-81 & -6.92 & -3.72 & -3.87 & -3.31 & -12.31 & 61.17 & 44.98 \\
\hline Aas-2011x Marvi- & -3.03 & -3.70 & -3.72 & \\
2000 & 3.45 & 2.74 & 5.77 & 4.76 & 1.56 & -5.79 & 50.00 & 25.00 \\
\hline Pak-81 x Marvi-2000 & & & & & & & &
\end{tabular}

Table 3. Heterotic effects of $F_{1}$ hybrids over their mid and better parents for peduncle length, Spike length, spikelets spike ${ }^{-1}$, grains spike ${ }^{-1}$ in bread wheat (Triticum aestivum L.)

\begin{tabular}{|c|c|c|c|c|c|c|c|c|}
\hline \multirow{2}{*}{ F1 Crosses } & \multicolumn{2}{|c|}{$\begin{array}{c}\text { Peduncle length } \\
\text { (cm) }\end{array}$} & \multicolumn{2}{c|}{$\begin{array}{c}\text { Spike length } \\
\text { (cm) }\end{array}$} & \multicolumn{2}{c|}{ Spikelets spike-1 $^{-1}$ Grains spike-1 $^{-1}$} \\
\cline { 2 - 9 } & $\begin{array}{c}\text { Mid } \\
\text { parent }\end{array}$ & $\begin{array}{c}\text { Better } \\
\text { parent }\end{array}$ & $\begin{array}{c}\text { Mid } \\
\text { parent }\end{array}$ & $\begin{array}{c}\text { Better } \\
\text { parent }\end{array}$ & $\begin{array}{c}\text { Mid } \\
\text { parent }\end{array}$ & $\begin{array}{c}\text { Better } \\
\text { parent }\end{array}$ & $\begin{array}{c}\text { Mid } \\
\text { parent }\end{array}$ & $\begin{array}{c}\text { Better } \\
\text { parent }\end{array}$ \\
\hline Sunco x Janbaz & 38.16 & 24.44 & 27.03 & 16.74 & 20.16 & 16.82 & 20.00 & 17.12 \\
\hline Sunco x WL-711 & 18.79 & 10.81 & 18.70 & 5.64 & 16.33 & 15.87 & 18.60 & 17.65 \\
\hline Sunco x Aas-2011 & 14.42 & 2.58 & 13.13 & 3.70 & 6.56 & 3.00 & 9.71 & 7.73 \\
\hline Sunco x Pak-81 & 16.08 & 12.76 & 16.72 & 8.20 & 13.36 & 12.02 & 17.91 & 14.44 \\
\hline Sunco x Marvi-2000 & 11.75 & 11.13 & 20.35 & 4.71 & 3.59 & 3.17 & 7.07 & 5.35 \\
\hline Janbaz x WL-711 & 7.22 & -9.19 & 5.99 & 2.29 & 18.85 & 15.08 & 21.55 & 19.57 \\
\hline Janbaz x Aas-2011 & -17.26 & -32.33 & 4.64 & 4.32 & 9.52 & 3.00 & 11.29 & 6.70 \\
\hline Janbaz x PAK-81 & 25.55 & 16.12 & 8.46 & 7.43 & 18.33 & 16.41 & 20.34 & 19.67 \\
\hline Janbaz x Marvi-2000 & 19.27 & 7.98 & 21.14 & 14.04 & 26.23 & 22.22 & 28.69 & 27.63 \\
\hline WL-711 x Aas-2011 & 13.39 & 8.61 & 23.58 & 19.63 & 18.46 & 14.94 & 22.75 & 19.58 \\
\hline WL-711 x Pak-81 & 22.80 & 11.52 & 9.97 & 5.18 & 13.71 & 11.90 & 19.44 & 16.85 \\
\hline WL-711 x Marvi- & 11.03 & 3.05 & 12.77 & 9.87 & 9.52 & 9.52 & 20.00 & 19.03 \\
\hline 2000 & 20.35 & 5.16 & 13.13 & 11.73 & 14.06 & 8.97 & 18.92 & 13.40 \\
\hline Aas-2011 x Pak-81 & 7.73 & -3.89 & 10.34 & 4.17 & 11.54 & 8.23 & 16.80 & 12.88 \\
\hline Aas-2011x Marvi- & 2000 & & & & & & 27.17 & 25.42 \\
\hline Pak-81 x Marvi-2000 & 24.33 & 21.44 & 19.27 & 11.29 & 20.97 & 19.05 & \\
\hline
\end{tabular}


Table 4. Heterotic effects of $F_{1}$ hybrids over their mid and better parents for grain weight spike $^{-1}$, seed index, grain yield in bread wheat (Triticum aestivum L.)

\begin{tabular}{|c|c|c|c|c|c|c|}
\hline \multirow{2}{*}{$F_{1}$ Crosses } & \multicolumn{2}{|c|}{ Grain weight spike $^{-1}$} & \multicolumn{2}{|c|}{ Seed index } & \multicolumn{2}{|c|}{ Grain yield } \\
\hline & $\begin{array}{c}\text { Mid } \\
\text { parent }\end{array}$ & Better parent & $\begin{array}{c}\text { Mid } \\
\text { parent }\end{array}$ & Better parent & $\begin{array}{c}\text { Mid } \\
\text { parent }\end{array}$ & Better parent \\
\hline Sunco x Janbaz & 38.16 & 24.44 & 27.03 & 16.74 & 20.16 & 16.82 \\
\hline Sunco x WL-711 & 18.79 & 10.81 & 18.70 & 5.64 & 16.33 & 15.87 \\
\hline $\begin{array}{c}\text { Sunco x Aas- } \\
2011\end{array}$ & 14.42 & 2.58 & 13.13 & 3.70 & 6.56 & 3.00 \\
\hline Sunco x Pak-81 & 16.08 & 12.76 & 16.72 & 8.20 & 13.36 & 12.02 \\
\hline $\begin{array}{c}\text { Sunco x Marvi- } \\
2000 \\
\end{array}$ & 11.75 & 11.13 & 20.35 & 4.71 & 3.59 & 3.17 \\
\hline Janbaz x WL-711 & 7.22 & -9.19 & 5.99 & 2.29 & 18.85 & 15.08 \\
\hline $\begin{array}{c}\text { Janbaz x Aas- } \\
2011 \\
\end{array}$ & -17.26 & -32.33 & 4.64 & 4.32 & 9.52 & 3.00 \\
\hline Janbaz x PAK-81 & 25.55 & 16.12 & 8.46 & 7.43 & 18.33 & 16.41 \\
\hline $\begin{array}{c}\text { Janbaz x Marvi- } \\
2000 \\
\end{array}$ & 19.27 & 7.98 & 21.14 & 14.04 & 26.23 & 22.22 \\
\hline $\begin{array}{c}\text { WL-711 x Aas- } \\
2011\end{array}$ & 13.39 & 8.61 & 23.58 & 19.63 & 18.46 & 14.94 \\
\hline $\begin{array}{c}\text { WL-711 x Pak- } \\
81\end{array}$ & 22.80 & 11.52 & 9.97 & 5.18 & 13.71 & 11.90 \\
\hline $\begin{array}{c}\text { WL-711 x } \\
\text { Marvi-2000 }\end{array}$ & 11.03 & 3.05 & 12.77 & 9.87 & 9.52 & 9.52 \\
\hline $\begin{array}{c}\text { Aas-2011 x Pak- } \\
81\end{array}$ & 20.35 & 5.16 & 13.13 & 11.73 & 14.06 & 8.97 \\
\hline $\begin{array}{c}\text { Aas-2011x } \\
\text { Marvi-2000 }\end{array}$ & 7.73 & -3.89 & 10.34 & 4.17 & 11.54 & 8.23 \\
\hline $\begin{array}{c}\text { Pak-81 x Marvi- } \\
2000 \\
\end{array}$ & 24.33 & 21.44 & 19.27 & 11.29 & 20.97 & 19.05 \\
\hline
\end{tabular}

\section{Analysis of variance}

The mean squares from analysis variance for genotypes, including parents, hybrids, parents, and hybrids, were significantly different for all traits. These results showed that all data could be processed for further analysis in order to evaluate heterotic effects in $\mathrm{F}_{1}$ hybrids.

\section{Days to 50\% heading}

Heterosis and heterobeltiosis for days up to $50 \%$ of the course are presented in (Table 2). The result showed that only one $F_{1}$ hybrid showed undesirable positive mid-parent heterosis

and another one expressed positive but zero average parent heterosis out of fifteen $F_{1}$ hybrids. The maximum unwanted positive mid-parent heterosis was observed in Pak-81 x Marvi-2000 and WL-711 x Marvi-2000, while the most desirable negative mid-parent heterosis was shown with a cross WL-711 $\mathrm{x}$ Aas-2011 and then a cross Janbaz x Aas 2011, while zero heterosis was observed in the Sunco x Marvi-2000 cross. The most advantageous negative best parent heterosis was shown by the cross WL-711 x Aas-2011, followed by the cross Janbaz x Aas-2011, while the positive unprofitable the best parent heterosis was registered by the Pak- $81 \mathrm{x}$ Marvi-2000 cross pack and the following points were recorded using the WL-711 x Marvi-2000 cross, and the least desirable negative heterobeltiosis was demonstrated using the Sunco x Marvi-2000 cross. 


\section{Days to $75 \%$ maturity}

Heterosis studies shown in (Table 2) revealed that the majority of the $F_{1}$ hybrids gave desirable negative mid-parent heterosis while only three crosses expressed nonadvantageous positive relative heterosis. The maximum relative heterosis was observed in cross Pak-81 x Marvi-2000 while Sunco x Marvi-2000 ranked second in expressing undesirable positive average parent heterosis. The greatest negative heterosis of the middle and middle level was demonstrated in WL$711 \times$ Aas-2011 and the minimum negative at the intersection of Sunco x Aas-2011. On the other hand, the greatest unwanted positive heterobeltiosis was expressed by cross-Pak81 x Marvi-2000, followed by WL-711 x Marvi-2000. While the highest, but desirable negative best parent heterosis was expressed by the Janbaz x Aas-2011 hybrid, the lowest desired negative best parent heterosis was observed in cross-Aas-2011 x Marvi-2000.

\section{Plant height}

The calculations of heterotic effects for plant height presented in (Table 2) showed that the highest but undesirable positive relative heterosis was recorded by WL-711 x Aas2011 and next was Sunco x Janbaz. However, the most desirable negative mid-parent heterosis was demonstrated by Janbaz x Aas2011 crossover. As for heterobeltiosis, the maximum unfavorable positive heterosis with the best parent was recorded WL-711 x Pak-81, then WL-711 x Aas-2011. While the highest and lowest desirable negative best parent heterosis were expressed Janbaz $\mathrm{x}$ Aas-2011 and Pak-81 x Marvi-2000, respectively. Whereas the lowest desirable negative mid-parent heterosis was observed in Aas-2011 x Marvi-2000.

Number of tillers plant ${ }^{-1}$

Heterotic effects in $F_{1}$ hybrids for a number of plant ${ }^{-1}$ are listed in the table (Table 2). These results showed that all hybrids showed positive values for relative heterosis and heterobeltiosis. The results showed positive average parent heterosis for all crosses, however, the highest average parent heterosis was registered Sunco x Marvi-2000, then Sunco $\mathrm{x}$ Janbaz, but the lowest positive average parent heterosis was demonstrated by the cross Janbaz $x$ WL-711. For heterobeltiosis, the highest positive heterosis with the best parent was registered with the Sunco x Janbaz cross, while the smallest best parent heterosis was registered with the WL711 x Marvi-2000 cross.

\section{Peduncle length}

Results regarding heterotic effects for peduncle length are displayed in (Table 3). Results indicated that all the $\mathrm{F}_{1}$ hybrids revealed positive values for average parent heterosis and best parent heterosis, except one which expressed negative mid-parent heterosis shown by cross Janbaz x Aas-2011 and three expressed negative best parent heterosis. The highest negative heterosis was shown on Janbaz x Aas-2011 cross, and the lowest negative on Cross Aas-2011 x Marvi2000 . However, the highest positive heterosis of the middle and parental levels was expressed by the crossover Sunco x Janbaz $(38.16 \%)$ and the heterosis of the best parent section Sunco x Janbaz.

\section{Spike length}

The heterosis for spike length is summarized in (Table 3). The results showed that all the $F_{1}$ hybrids expressed positive effects for relative heterosis and heterobeltiosis. The results showed that the positive average parent heterosis was expressed by all crosses, however, the highest average parent heterosis was recorded by Sunco x Janbaz, and the next high score was WL-711 x Aas-2011, which revealed heterosis, but the lowest positive average was shown heterosis on the cross Janbaz x Aas-2011. As for heterobeltiosis, the highest positive heterosis with the best parent was recorded by the cross WL-711 $\mathrm{x}$ Aas-2011, and then Sunco $x$ Janbaz. However, the lowest positive, best parental 
heterosis was recorded by Janbaz x WL-711 cross.

\section{Spikelets spike ${ }^{-1}$}

The heterotic effects in $\mathrm{F}_{1}$ hybrids for spike ${ }^{-1}$ spikelets are summarized in (Table 3). Such results showed that all the $\mathrm{F}_{1}$ hybrids expressed positive values for relative heterosis and heterobeltiosis. In addition, the results showed positive heterosis of the middle parent for all crosses, however, the highest heterosis of the middle parent was recorded by Janbaz x Marvi-2000, and then Pak-81 x Marvi-2000, and the smallest positive heterosis of the middle parent was shown by Sunco x Marvi 2000. As for heterobeltiosis, the highest positive heterosis from parents was registered by cross-test Janbaz x Marvi-2000. The smallest best parent heterosis was marked by the Janbaz $\mathrm{x}$ Marvi-2000 and Sunco x Aa-2011 crosses.

\section{Number of Grains spike ${ }^{-1}$}

Heterotic effects in $F_{1}$ hybrids for grains spike $^{-1}$ are shown in (Table 3). The results indicated that all the $\mathrm{F}_{1}$ hybrids expressed positive relative heterosis and heterobeltiosis. Results showed a positive average parent heterosis for all crosses, but the highest average parent heterosis was measured in Janbaz x Marvi-2000, and the second ranking was WL-711 $x$ Aas-201, and the lowest positive average parent heterosis was measured in Sunco x Marvi -2000 Regarding heterobeltiosis, the highest positive heterosis with the best parental trait was registered using the Sunco x Marvi-2000 cross, and then with the Pak-81 x Marvi-2000, while the smallest positive heterosis with the best parental trait was recorded using Sunco $\mathrm{x}$ Marvi 2000 cross.

\section{Grain weight spike ${ }^{-1}$}

The heterotic effects of $F_{1}$ hybrids compared to their average and best parents in relation to the mass of grain spike ${ }^{-1}$ in hexaploid wheat are shown in (Table 4). Of the fifteen hybrids, four showed negative relative heterosis, while for heterobeltiosis, seven had negative heterosis from the best parents. The largest negative heterosis among the middle parent was observed in Janbaz $x$ Aas-2011 and heterobeltiosis in the Pak-81 x Marvi-2000 cross. While Janbaz x WL-711 and Janbaz x WL-711 crosses recorded the least negative relative heterosis and heterobeltiosis, respectively. However, the highest positive average heterosis was observed in Sunco $\mathrm{x}$ Pak-81 (49.84\%) and the maximum heterobeltiosis in the Sunco x Pak-81 cross.

\section{Seed index}

Heterotic effects regarding for seed index are displayed in (Table 4). The results show that all $F_{1}$ hybrids showed positive values for the heterosis of the middle parent and the heterosis of the best parent, except for one that expressed the negative heterosis of the middle parent in Janbaz x Aas-2011 cross, while four expressed the best parent negative heterosis. The largest negative heterosis was demonstrated by Janbaz x Aas-2011 cross and the smallest by WL-711 x Marvi-2000 cross. Whereas the highest positive heterosis of the middle and best parent was expressed by the Sunco x Pak-81 cross.

\section{Grain yield plant ${ }^{-1}$}

The results of heterotic effects in $F_{1}$ hybrids for grain yield of plants ${ }^{-1}$ are presented in (Table 4). The results showed that all $\mathrm{F}_{1}$ hybrids showed positive values for relative heterosis and heterobeltiosis. In addition, the results showed that at all crosses a positive heterosis of the middle and parental levels was found, however, the highest heterosis of the middle and middle levels was measured in Sunco x Janbaz, and the next ranking was Janbaz x Pak-81, while positive mean and baseline heterosis was measured in WL-711 $x$ Marvi 2000. For heterobeltiosis, the highest positive heterosis with a higher parent level was recorded in the Sunco x Janbaz cross, followed by Janbaz x Pak-81. Whereas the smallest positive, the best parental heterosis was registered Janbaz x Marvi-2000, WL- 
711 x Marvi-2000 and Pak-81 x Marvi-2000 with the same heterotic value.

\section{Discussion}

The present research, therefore, was carried out to determine the heterotic effects in $F_{1}$ hybrids for different economic traits from half-diallel crosses of six bread wheat cultivars. The results of the analysis variance are summarized in (Table 1). Results concerning heterosis for various characters of yield and yield traits are presented in (Tables 2-4). Results are discussed by nature, as under:

Heterosis for days to $50 \%$ heading is given in (Table 2). The results showed that all the crosses exhibited desirable negative days to $50 \%$ heading over mid parent as well as better parent values except two $F_{1}$ hybrids, i.e. Pak81 x Marvi-2000 and WL-711 x Marvi-2000 which showed undesirable positive midparent heterosis of $3.45 \%$ and $2.54 \%$ respectively. While maximum undesirable positive better parent heterosis was found in Pak-81 x Marvi-2000 (2.74\%) followed by WL-711 x Marvi-2000 (2.31\%). The positive estimates of heterosis and heterobeltiosis are not desired because the early heading is desirable due to the fact that earlier heading will lead to earlier maturity, hence crop can be saved from the late hot period,fewer inputs will be used and field will be vacated well in time for growing next crop. The negative heterosis for days to heading is therefore useful. Comparable results were obtained by $[21,22]$ who reported negative heterosis for days to $50 \%$ heading.

Results for heterosis (Table 2) revealed that majority of the $F_{1}$ hybrids expressed desirable negative mid-parent heterosis while only three crosses expressed undesirable positive relative heterosis, the maximum was recorded in cross Pak-81 x Marvi-2000 (5.77\%) while, Sunco x Marvi-2000 ranked next in manifesting undesirable positive midparent heterosis of $(4.31 \%)$. The highest advantageous negative mid-parent heterosis
(-9.32\%) was shown by WL-711 x Aas-2011 while minimum (-3.50\%) was exhibited by cross Sunco x Aas-2011. On the other hand, the highest undesirable positive heterobeltiosis was expressed by cross Pak81 x Marvi-2000 (4.76\%) followed by WL711 x Marvi-2000 (3.85\%). Whereas the highest advantageous negative better-parent heterosis $(-8.57 \%)$ was expressed by Janbaz $\mathrm{x}$ Aas-2011 yet, the lowest desirable negative better-parent heterosis (-3.87\%) was observed in Aas-2011 x Marvi-2000. Days up to $75 \%$ of maturity mean days spent on full physiological maturation. The genotypes with the habit of early maturity are desirable, therefore negative heterosis during the days up to $75 \%$ of maturity is useful. The results showed that crosses WL-711 x Aas-2011 and Sunco x Aas-2011 exhibited superior negative better parent heterosis for days to 75 $\%$ maturity. Comparable positive results were also obtained by [21, 22] while reported negative heterosis for days to $75 \%$ maturity which is in conformity with our results. Heterotic studies (Table 2) revealed that out of fifteen hybrids, seven $F_{1}$ hybrids showed an increase over the mid-parent while 8 crosses gave reductions in plant height. The crosses showed a substantial increase in plant height as compared to respective midparental value i.e. WL-711 x Aas-2011 $(9.15 \%)$ and Sunco x Janbaz (8.71\%). The cross combination which exhibited maximum advantageous negative heterosis was Janbaz x Aas-2011 (-15.59\%). Desirable negative heterobeltiosis was exhibited by 9 crosses out of 15 hybrids. Nevertheless, maximum negative heterobeltiosis was found in crosses Janbaz x Aas-2011 (-21.88\%), Sunco x Aas-2011 (-15.72\%) and WL-711 x Marvi-2000 (-14.64\%). Negative estimates of heterosis and heterobeltiosis for plant growth are preferable when growing wheat since dwarfism is a desirable character [23]. In some crosses where heterobeltiosis was observed in which over-dominance might be 
involved, thus effective selection of desirable recombinants from this material is possible in later generations. Similar to our results, [24, 25] also reported positive heterosis while [22, $26,27]$ observed negative heterosis for plant height during their study on wheat.

Fertile tillers per plant are an important component of the crop, and its positive heterosis is useful in wheat breeding programs. The calculation of heterotic effects for number of tillers plant ${ }^{-1}$ was presented in (Table 2) which showed that all the $F_{1}$ hybrids recorded positive heterotic effects for number of tillers per plant. Maximum relative heterosis was found in crosses Sunco $\mathrm{x}$ Marvi-2000 (89.47\%) and Sunco x Janbaz (86.67\%). Crosses showing high heterobeltiosis in order were; Sunco x Janbaz (82.53\%) and Sunco x Marvi-2000 (63.71\%) for number of tillers per plant $[22,28]$ It is also of the opinion that middle and best parental heterosis for tillers can be obtained in wheat. Consequently, the crosses confirming the maximum heterosis were Sunco x Marvi-2000 and Sunco x Janbaz, which could be used to obtain an improved yield in bread wheat.

Heterotic effects depicted in (Table 3) revealed that 14 out of $15 \quad \mathrm{~F}_{1}$ hybrids expressed positive mid-parent heterosis. Nonetheless, maximum positive heterosis was found in crosses Sunco $\mathrm{x}$ Janbaz (38.16\%) and Janbaz x Pak-81 (25.55\%) whereas $F_{1}$ hybrid Janbaz $x$ Aas-2011 exhibited negative mid-parent heterosis ($17.26 \%)$. Positive heterobeltiosis was found in $13 \mathrm{~F}_{1}$ hybrids while the other two hybrids depicted negative better parent heterosis for peduncle length. Maximum positive heterobeltiosis was found in crosses Sunco $\mathrm{x}$ Janbaz (24.44\%) and Pak-81 x Marvi-2000 $(21.44 \%)$. These results are in accordance with those $[29,30]$.

Heterotic effects presented in (Table 3) revealed positive relative heterosis was observed in all the $\mathrm{F}_{1}$ hybrids. Nonetheless, maximum positive relative heterosis was found in crosses Sunco x Janbaz (27.03\%) and WL-711 x Aas-2011 (23.58\%). whereas Janbaz x Aas-2011 (4.64\%) gave minimum heterosis. Positive better parent heterosis was also found in all $\mathrm{F}_{1}$ hybrids, however, maximum positive better parent heterosis was found in crosses WL-711 x Aas-2011 $(19.63 \%)$ and Sunco x Janbaz (16.74\%). These findings are closely related to the findings of $[22,25]$ who reported positive heterosis, yet negative heterosis was also found by [26].

Information regarding the heterosis, the increase over the mid-parent was indicated by all fifteen cross combinations (Table 3 ). Maximum positive relative heterosis was found in crosses Janbaz $x$ Marvi-2000 (26.23\%) and Pak-81 x Marvi-2000 (20.97\%) whereas also positive heterobeltiosis was also observed in all fifteen $\mathrm{F}_{1}$ hybrids. However, maximum positive heterobeltiosis was noted in $\mathrm{F}_{1}$ hybrids Janbaz x Marvi-2000 (22.22\%) followed by Pak-81 x Marvi-2000 (19.05\%) yet, Sunco x Marvi-2000 (3.00\%) and Sunco x Aas-2011 (6.56\%) showed minimum better parent heterosis for spikelets spike ${ }^{-1}$. Positive heterosis is desirable for spikelets spike ${ }^{-1}$ because denser spike may produce more spikelets per spike, thus may have more no. of grains. Comparable results were also obtained by $[17,31,32]$ who reported positive heterosis for spikelets spike ${ }^{-1}$.

The heterotic effects for number of grains per spike presented in (Table 3) showed that all the $F_{1}$ hybrids recorded positive heterotic effects for the number of grains per spike. The two top scorings were Janbaz x Marvi2000 and WL-711 x Aas-2011 (28.69\% and $22.75 \%$ ) for relative heterosis while for heterobeltiosis, the two top rankers were; Janbaz x Marvi-2000 (27.63\%) and Pak-81 x Marvi-2000 (25.42\%) respectively, among the $\mathrm{F}_{1}$ hybrids. These results suggest that Janbaz x Marvi-2000 and WL-711 x Aas2011 hybrids can be used for the 
development or selection of hybrid crops in a later generation to improve the number of grains per ear, and hence the yield of grain. Our findings are in conformity with those of $[22,33]$ who also noted positive heterosis. The heterotic effects for grain weight spike ${ }^{-1}$ presented in (Table 4) showed that from fifteen $F_{1}$ hybrids, twelve recorded positive heterotic effects for grain weight spike ${ }^{-1}$. The two top scorers were Sunco $x$ Pak-81 (49.84\%) and Sunco x WL-711 (34.79\%) for relative heterosis and Sunco $\mathrm{x}$ Pak-81 (40.93\%) and WL-711 x Pak-81 (17.88\%) for heterobeltiosis respectively for grain weight spike $^{-1}$ among the $F_{1}$ hybrids. This suggests that the hybrids Sunco x Pak-81 and Sunco $\mathrm{x}$ WL-711 can be used for the development of hybrid crops or breeding in a later generation to improve the weight of grain per ear, and hence the grain yield. Our findings are in conformity with those of $[32,34]$ who also noted positive heterosis for this trait.

A perusal of results shown in (Table 4) indicated that 14 crosses showed an increase in 1000-grain weight over their mid-parent value, however, crosses Sunco x Pak-81 (23.34\%) and Sunco x Janbaz (21.40\%) expressed maximum positive heterosis in 1000-grain weight. Positive heterobeltiosis was also revealed by 11 crosses out of 15 hybrids, yet maximum positive heterobeltiosis was found in crosses Sunco $\mathrm{x}$ Pak-81 (20.21\%) and Sunco x Janbaz (16.68\%) for 1000-grain weight. Present findings are in conformity with those of [25, 28] who also reported positive heterosis and heterobeltiosis for seed index.

Heterosis on grain yield of plants ${ }^{-1}$ is given in (Table 4). The results showed that all $F_{1}$ hybrids showed an increase in grain yield in plant $^{-1}$ compared with the average baseline and the best baseline value. The crosses showing highest increases in grain yield plant $^{-1}$ as compared to respective midparental values were: Sunco $\mathrm{x}$ Janbaz (100.00\%), Janbaz x Pak-81 (76.32\%) and
Sunco x Pak-81 (71.89\%) while maximum positive heterobeltiosis were found in Sunco x Janbaz (94.74\%), Janbaz x Pak-81 (76.32\%) and Sunco x Pak-81 (67.37\%). The utilization of reported best cross combinations in the hybrid wheat breeding program could be an effective approach for the improvement of grain yield. These results are in agreement with those of $[22,25,27,28]$ who also reported positive heterosis for grain yield plant ${ }^{-1}$ in wheat.

\section{Conclusion}

The results for relative heterosis revealed that among the $\mathrm{F}_{1}$ hybrids, maximum desirable negative relative heterosis $(-10.70 \%)$ and ($8.97 \%$ ) were exhibited by $\mathrm{F}_{1}$ hybrids WL-711 x Aas-2011 and Janbaz x Aas-2011 for days to $50 \%$ heading, cross WL-711 x Aas-2011 also exhibited desirable negative heterosis ($9.32 \%$ ) for days to $75 \%$ maturity; Janbaz $\mathrm{x}$ Aas-2011 exhibited the highest negative ($15.59 \%$ ) relative heterosis for plant height in the desired direction. Maximum positive relative heterosis $(89.47 \%)$ was displayed by the hybrid Sunco x Marvi-2000 for number of tiller plant ${ }^{-1}$ followed by Sunco x Janbaz (86.67\%); Sunco x Janbaz for peduncle length $(38.16 \%)$, spike length $(27.03 \%$ and highest grain yield plant ${ }^{-1}(100.00 \%)$; Janbaz x Marvi-2000 for spikelets spike ${ }^{-1}(26.23 \%)$ and grains spike ${ }^{-1}(28.69 \%)$; Sunco x Pak-81 for grain weight plant $^{-1}(49.89 \%)$ and seed index $(23.34 \%)$. In $F_{1}$ hybrids, maximum desirable negative heterobeltiosis of $-2.63 \%$ was displayed by hybrid Sunco x Marvi-2000 for days to 50\% heading; Janbaz x Aas-2011 for days to $75 \%$ maturity $(-8.57 \%)$ and plant height $(-21.88 \%)$ in the desired direction. Maximum positive heterobeltiosis $(82.53 \%)$ was displayed by hybrid Sunco x Janbaz for number of tiller plant $^{-1}$, peduncle length $(24.44 \%)$ and grain yield plant ${ }^{-1}(94.74 \%)$; WL-711 x Aas-2011 for spike length (19.63\%); Janbaz x Marvi-2000 for spikelets $\operatorname{spike}^{-1}(22.22 \%)$ and grains spike ${ }^{-1}(27.63 \%)$; Sunco x Pak-81 for grain weight spike $^{-1}$ 
$(40.93 \%)$ and seed index $(20.21 \%)$. These crossings revealed good opportunities for their commercial use of heterosis, as well as for distinguishing clean lines among descendants in subsequent segregational generations of bread wheat.

\section{Authors' contributions}

Conceived and designed the experiments: AA Khokhar \& HF Wang, Performed the experiments: AA Khokhar, FG Nizamani, RA Rind, MM Nizamani, A Mehmood \& MU Khokhar, Analyzed the data: AA Khokhar, WA Jatoi \& MM Nizamani, Contributed reagents/ materials/ analysis tools: A Mehmood \& MU Khokhar, Wrote the paper: AA Khokhar.

\section{References}

1. Heyne EG, Briggle LW \& Curtis BC (1987). Wheat Worldwide. Agronomy Monograph.doi:10.2134/agronmonogr1 3.2ed.c1

2. Pakistan: Grain and Feed Update USDA Foreign Agricultural Service, July 2018, Gain report number PK1823, pp 4. www.fas.usda.gov/data/pakistan-grainand-feed-update-9

3. Sharma I, Shoran J, Singh G \& Tyagi B.S (2011). Wheat improvement in India. Souvenir of 50th all India wheat and barley research workers, pp 11. New Delhi.

4. Gallais A (1988). Heterosis its genetic basis and its utilisation in plant breeding. Euphytica 39: 95-104.

5. Kearsey MJ (1965). Biometrical analysis of a random mating population. A comparison of five experimental designs. Heredity 20(2): 205-235.

6. Griffing B (1956). Concept of general versus specific combining ability in relation to diallel crossing system. Aust J Biol Sci 9: 463-493.

7. Gardner CO \& Eberhart, SA (1966). Analysis and Interpretation of the Variety Cross Diallel and Related Populations. Biometrics 22(3): 439.
8. Singh M, Devi EL, Aglawe S, Kousar N \& Behera C (2013). Estimation of heterosis in deffreent crosses of bread wheat (Triticum aestivum L). The Biasean 8(4): 1393-1401.

9. Singh RC (2004). Importance of wheat crop in India, Annals of Biol 16(1): 95100.

10. Shull GF (1908). The composition of a field of maize. Rep Am Breed Assoc 5: 51-59.

11. Freeman GF (1919). Heredity of quantitative characters in wheat. Genetics 4: 1-93.

12. Briggle LW (1963). Heterosis in wheatA review. Crop Sci 3: 407-412

13. Kumar V, Mishra K, Vyas RP \& Singh $\mathrm{V}$ (2011). Heterosis and combining ability analysis in bread wheat (Triticum aestivum L.). J Pl Breed. Crop Sci 3(10): 209-217.

14. Rauf S, Shahzad M, Teixeira da Silva JA \& Noorka IR (2012). Biomass partitioning in sunflower inbred lines and hybrids under contrasting saline regimes. J Crop Sci and Biot 15(3): 5357.

15. Fabrizius MA, Busch RH \& Khan K (1998). Genetic diversity and heterosis of spring wheat crosses. Crop Sci 38: 1108-1112.

16. Gowda M, Kling C, Wurschum T, Liu W, Maurer HP, Hahn V \& Reif JC (2010). Hybrid breeding in durum wheat: Heterosis and Combining Ability. Crop Sci 50: 2224-2230.

17. Kalhoro FA, Rajpar AA, Kalhoro SA, Mahar A \& Ali A (2015). Heterosis and combing ability in $\mathrm{F}_{1}$ population of hexaploid wheat (Triticum Aestivum L.). American J PL Sci 6: 1011-1026.

18. Gomez KA \& Gomez AA (1984). Statistical procedure for Agriculture Research. John wiely and sons Inc., $2^{\text {nd }}$ (ed) New York USA.

19. Singh RK \& Choudhary BD (1979). 
Biometrical Methods in Quantitative Genetic Analysis (Revised. 1979). Kalyani Publisher, New Delhi, pp 191200.

20. Fehr RW (1987). Principles of Cultivar Developments.Theory and Technique. Pp: 115-116. Macmillan Publishing Company, Inc. New York, USA.

21. Shehzad T, Khalil IH, Shah SMA, Ihsan H \& Swati MS (2005). Heterosis estimates for some morphological traits in spring wheat crosses. Sarhad J Agric 21(1): 33-39.

22. Jaiswal KK, Pandey $P$, Marker $S \&$ Anurag PJ (2010). Heterosis studies for improvement in yield potential of wheat (Triticum aestivum L.). AAB Bioflux 2(3): 273-278.

23. Budak N \& Yildirim MB (1996). Heterosis in bread wheat (Triticum aetivum L.). Turk J Agric Fore 20: 345347.

24. Jan M, Hassan G, Khalil I \& Raziuddin (2005). Estimates of heterosis and heterobeltiosis for morphological traits in wheat (Triticum aestivum L). Pak J Biol Sci 8(9): 1261-1264.

25. Kashif M \& Khaliq I (2004). Manifestation of heterosis for some metric characters in intraspecific crosses of Triticum aestivum L. Inter J Agric \& Biol 6(1): 132-137.

26. Bhutta WM, Akhtar J, Anwar-ul-Haq M and Ibrahim M (2005). Estimation of heritability of some important traits in spring wheat (Triticum aestivum L.). Santa Cruz do Sul 17(1): 21-27.

27. Khattab SAM, Esmail RM and ALAnsary AMF (2010). Genetical analysis of some quantitative traits in bread wheat (Triticum aestivum L). New York Sci J 3(11): 152-157.

28. Hussain F, Hussein M, Iqbal MM, Akhtar MA, Zulkiffal M \& Riaz-ud-Din (2007). Heterosis studies in wheat crosses. J Agric Res 45(4): 337-343.

29. Khan AS, Khan MKR \& Muhammad T (2000). Genetic analysis of plant height, grain yield and other traits in wheat (Triticum aestivum L.) Inter J Agri Biol 2(1):1560-8530.

30. Nookra, IR, Batool A, Rauf SJ, Saliva T \& Ashraf E (2013). Estimation of heterosis in wheat (Triticum aestivum L.) under contasting water regimes. Inter $J$ Plant Breeding 7(1): 55-60.

31. Akbar JA, Hussain M, Iqbal MM \& Sabir W (2010). Heterosis and heterobeltiosis for grain yeild improvement in bread wheat. J Agri Res 48(1): 15-23.

32. Ilker E, Tonk AF \& Tosun M (2010). Heterosis for yield and its components in bread wheat crosses among powdery mildew resistant and susceptible genotypes. Pak J Bot 42(1): 513-522.

33. Khattab SAM, Esmail RM \& AL-Ansary AMF (2010). Genetical analysis of some quantitative traits in bread wheat (Triticum aestivum L). New York Sci. J 3(11): 152-157.

34. Beche E, Silva DLC, Pagliosa SE, Franke JCAM \& Benin GMG (2013). Hybrid performance and heterosis in early segregant populations of Brazilian spring wheat. Aus J Crop Sci 7(1): 51-57. 